\title{
Multimodal representations of gender in young children's popular culture
}

\section{Fredrik Lindstrand, Eva Insulander, and Staffan Selander}

MedieKultur 2016, 61, 6-25

Published by SMID | Society of Media researchers In Denmark | www.smid.dk The online version of this text can be found open access at www.mediekultur.dk

\begin{abstract}
This article poses questions regarding learning and representation in relation to young children's popular culture. Focusing on gender, the article builds on multimodal, social semiotic analyses of two different media texts related to a specific brand and shows how gender and gender differences are represented multimodally in separate media contexts and in the interplay between different media. The results show that most of the semiotic resources employed in the different texts contribute in congruent ways to the representation of girls as either different from or inferior to boys. At the same time, however, excerpts from an encounter with a young girl who engages with characters from the brand in her role play are used as an example of how children actively make meaning and find strategies that subvert the repressive ideologies manifested in their everyday popular culture.
\end{abstract}

\section{Keywords}

Apps, children, gender, learning, multimodality, popular culture, social semiotics, television 


\section{Introduction}

Needless to say, the contemporary media landscape seems to offer young children a vast range of possibilities today. Internet and digital media provide a multitude of options in terms of activities, interaction and consumption. For those with the economic, technological and social means (cf. Buckingham \& Willett, 2013), there is a rich treasure chest of stories, characters, services and products on offer, waiting for them to invest their time and interest. Additionally, based on the globalisation of 'the market' and related to the continuous development of what Jenkins (2006) refers to as 'convergence culture', the cultural logic behind 'international trans-media' or 'cross-media franchises' (Aarseth, 2006; Jenkins, 2006; Lemke, 2004, 2009) has resulted in a parallel stream of toys and other products related to the media texts with which children are invited to engage. The combination of media texts and related 'material' artefacts enables children to choose the particular popular cultural pond into which to plunge.

When we first approached the field of younger children's popular culture in a research project examining how 'the Middle Ages' are construed in different learning settings, we were interested in the potential of popular culture as a resource for learning.'

'Alice', a three-year-old girl at one of the Swedish preschools we visited, helped us delimit the scope of our interest further. She was down on her hands and knees and neighed like a horse as she was playing with a friend among the shoes, boots and Wellingtons in the entrance hall of her preschool. Our presence disrupted the play for a moment as she shifted her focus of attention towards us. The following conversation took place:

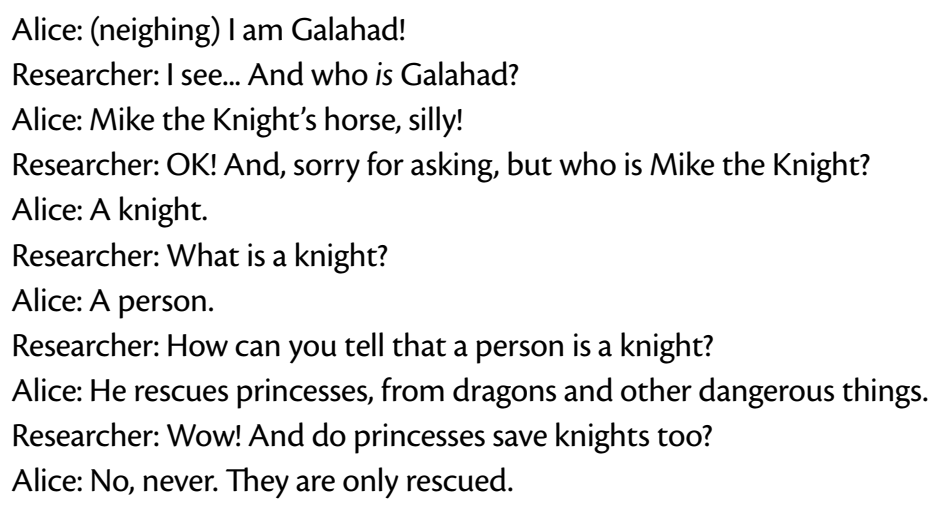

In conformity with what others have concluded before us regarding the potential of popular culture as a resource for learning (cf. Marsh et al., 2005; Buckingham, 2007), Alice's statement indicates that she has learned things. She has learned about specific characters within a specific brand and about the relationships between them. She also embodies some of this knowledge in her play as she creates a re-representation - using posture, movement and sound - of what kind of character 'Galahad' is. By combining these different modes in her work to represent (or signify) this character, her representation can be described as multimodal (cf. Kress \& van Leeuwen, 2001, p. 20). She has recognised certain potentials 
(affordances) in these specific modes that enable her to use them in ways that correspond with her intentions and interests within that situation. In that sense, modes are resources for representation (ibid., pp. 21-22; Kress, 2010, p. 79).

So far, her multimodal re-representation can be viewed as being in line with the way other scholars have discussed the relationship between popular culture and learning (or the development of specific skills and/or competencies) in relation to the language, communication and literacy curriculum (e.g., Buckingham, 2007; Gee \& Hayes, 2011; Marsh et al., 2005).

Apart from this, Alice's account of the relationship between knights and princesses shows that she also has learned something more general about relationships between different types of actors that populate the kinds of text with which she engages with and invests her interest in. These aspects differ from the kinds of knowledge and skills that usually are thought of in relation to the curriculum mentioned above, since they are closely connected to 'the social' in a more general sense.

The specific types of actors (knight and princess) that Alice mentions are closely associated with gender in children's contemporary popular culture. Knights are (usually) male, and - judging from products aimed at boys - boys are (probably) supposed or assumed to like/look up to/identify with knights. Princesses are (usually) female, and - judging from products aimed at girls - girls are (probably) supposed or assumed to like/look up to/identify with princesses. At least, that seems to be the guiding assumption behind the design and marketing of many products aimed at children today.

Alice's account of the relationship between knights and princesses implies a difference in their roles and their abilities (or freedom) to act: knights rescue while princesses are only rescued. Alice shows that she has learned that there is a social difference between (certain) characters associated with boys and (some of) those associated with girls.

At the same time, however, it is important to notice that Alice has chosen the role of the horse here - perhaps, motivated by the fact that it offers access to characteristics and possibilities that seem more positive to her during her play than other possible roles would? By working with the resources available to her in that situation (e.g., the choice of character and the set of modes she can use to play that part), she is able to deal with the tensions between the social rules conveyed through the set of representations that construe the fictitious world that she engages in and her own interests at the time (cf. Kress, 1997). ${ }^{2}$

There is no doubt that there is a general lack of balance in representations of gender in terms of who is represented and how they are represented in mainstream popular culture (cf. Sturken \& Cartwright, 2009, pp. 99-136). According to a report by Smith et al. (2013), only 28.3 pct. of the speaking characters in family films (and 30.8 pct. in children's television shows) are female. ${ }^{3}$ They also conclude that few stories are 'gender-balanced' and that only 11 pct. of family films show females in 45.1 to 55 pct. of all speaking roles. Instead, 50 pct. of family films and $39 \mathrm{pct}$. of children's shows cast boys or men in $75 \mathrm{pct}$. or more of the speaking roles (ibid.). Similar results were reported from a large quantitative study of children's 
television worldwide, showing a clear underrepresentation and stereotyped depiction of female characters worldwide (Götz et al., 2008). Others have come to similar conclusions in relation to other media, such as children's literature (e.g., Diekman and Murnen, 2004; Grauerholz \& Pescosolido, 1989) and children's picture books (e.g., Hamilton et al., 2006; Tepper \& Cassidy, 1999).

We see this as an important issue to address - particularly, in the context of children's popular culture, since representation is closely related to social action and the reproduction of hegemonic ideals (cf. Collins, 2000; Du Gay, 1997; Hall, 1997; Hodge \& Kress, 1988). As Richard Dyer (2000) concludes, representations in mainstream media not only reflect inequality and a lack of balance in society but also serve to define what certain groups and individuals can do and be in a given society (see also Rogoff, 2002). According to Dyer:

How a group is represented, presented over again in cultural forms, how an image of a member of a group is taken as representative of that group, how that group is represented in the sense of spoken for and behalf of (whether they represent, speak for themselves or not), these all have to do with how members of groups see themselves and others like themselves, how they see their place in society, their right to the rights a society claims to ensure its citizens.

(Dyer, 2000, p. 1)

The various aspects outlined above became the starting point for us to investigate issues regarding learning and representation in relation to children's popular culture. We have approached these issues through a series of analyses of a number of materials related to Mike the Knight, the specific brand Alice mentioned. The primary focus of this article is the construction of gender in the television series and a story-app for smartphones and tablets related to this brand.

\section{Our research questions}

Alice's account of the differences between knights and princesses, along with the results from the projects mentioned above, prompted us to approach the media texts with an assumption that there is probably something in them that implies a social difference between genders. Accordingly, our analyses were set up to answer the following questions: 1) is there anything in these particular media texts that implies a social difference between genders? 2) If there is, how is this performed (played out) in the texts? 3) Looking at the various materials as a trans-medial set, framed by the specific brand, how do different media texts designed for different platforms interplay in the representation of gender? 4) At a more general level, discussed in the concluding part of the article, what do the findings related to questions 2 and 3 above imply in terms of the potential of trans-medial popular culture as a resource for learning? 


\section{A theoretical framework for analysis}

The questions raised in this article regarding gender and representation in children's popular culture bring us close to areas successfully explored and theorized within the fields of feminist cultural studies and critical gender studies (cf. Butler, 1988, 1990; de Lauretis, 1987; DuCille, 1996; Jones, 1992, 2003).

However, while many analyses regarding these types of issues have focused on separate media texts or sets of texts within a specific medium (e.g., films, television shows, picture books, children's literature or digital games), our intention here is to draft an example of how gender is represented both within and across the various media texts and platforms with which young girls and boys engage today. We do so by looking at several media that are incorporated within and, thus, held together 'diegetically' by a specific brand. How is gender performed discursively in media texts for young audiences, and how are these performances enacted by means of the communicative and cultural resources afforded by the various media we investigate?

In order to approach these issues, we employ a multimodal, social semiotic approach (cf. Hodge \& Kress, 1988; Kress, 1993, 1997; 2003, 2010; Kress \& van Leeuwen, 2001, 2006; van Leeuwen, 2005) that enables us to do detailed analyses of how gender and gender differences are represented through different modes in a number of media. A central assumption here is that we construe the social world (e.g., roles, values, etc.) through our multimodal communication with each other. By representing aspects of the world discursively, we contribute to its construction accordingly. ${ }^{4}$ It is, therefore, important to investigate critically how the world is represented in different contexts through different media and different modes. The notion of 'mode' refers to the semiotic resources that are brought into play in the productive work to represent some aspect of the world in communication (Kress \& van Leeuwen, 2001, pp. 21-22). For example, we can use spoken and written language, gesture, image and sound in our communication with others. When two or more of these resources are combined - which they (probably) always are (cf. Baldry \& Thibault, 2006, p. 19) - our communication can be described as multimodal. Each mode does its particular semiotic work, and each has its distinct potential for meaning-making (Kress, 2010, p. 79). Another way of putting this is to say that different modes have different epistemological commitments (ibid., pp. 16-17, 166). They build on different logics in the way they can be used in representations. While syntax has an influence on how we can organise and interpret messages in language, composition affects meanings in images similarly. While syntax operates on a temporal axis and organises relationships between sequences of time, composition operates on a spatial axis and organises the relationship between elements in space. All modes are products of sociocultural work over time; and the more a specific mode has been used and refined within a certain social and cultural setting, the more detailed and specific are the meanings it can be used to articulate.

Since we wish to provide some concluding reflections regarding trans-medial popular culture as a possible resource for learning at the very end of this article, we also need to 
say something about how we approach learning. To begin with, we see learning as a transformative, unlimited and life-long process that takes place in and out of schools and other formal learning contexts (cf. Selander, 2008, 2015). It is a process in which we shape and modify our understanding in respect to various things. Kress (2010, p. 182) defines learning as:

the result of the transformative engagement with an aspect of the world which is the focus of attention by an individual, on the basis of principles brought by her or him to that engagement; leading to a transformation of the individual's semiotic/conceptual resources.

We learn about many different things at the same time, independently of what is conventionally regarded as 'true' or how the 'subject content' is defined. Apart from things pointed out by teachers or others, we are also individual beings who try to cope by relating to the situation, the topics in focus, and to each other. In that sense, there is always a social aspect of learning that is part of our continuous work with our identities. We may achieve more or less in relation to the prescribed learning objectives in a formal learning context of some kind but, simultaneously, learn about who we are in relation to others. In that sense, design always has both epistemological and social consequences: how we represent aspects of the world influences the possibilities learners have to make meaning and positions the learner socially, thus influencing their agency and their possibilities to relate to the things we represent.

In relation to the topics of this article, we assume that gender roles and worldviews are something learned from early on in life. From that perspective, popular culture - along with many other things - can be viewed as a learning resource. By looking at how gender is represented in different trans-medial texts that draw on different modal configurations, this article simultaneously investigates the possibilities and constraints of a particular set of trans-medial texts as a resource for learning.

\section{Mike the Knight - The brand}

Produced by HIT Entertainment, Mike the Knight started out as a British-Canadian animated television series created by Alexander Bar and written by Marc Seal. Since its first broadcast in 2011, it has been aired in a number of countries and regions across the world, e.g., North America, Latin America, Europe, Australia and New Zealand.

The main character of the series is 10-year-old Mike, who is a knight-in-training. He looks up to his father, the King, who is away exploring other lands. With his two dragon friends, Sparkie and Squirt, his sister Evie (a wizard apprentice), his horse Galahad and his friend Trollee, Mike tries to be the bravest knight of all. Throughout his adventures, he learns from the mistakes he makes - eventually realising, in every episode, how to 'be a knight - and do it right!' 
Following the logic of contemporary media culture, the concept behind the series has been expanded trans-medially to the production of games, apps, books, audiobooks and a website related to the series. It has also been widely expanded through media franchises, and the production company has so far sold approximately one hundred licenses in a vast number of product categories (Global License, www.licensemag.com).

At the time of our study, the series was aired regularly on the Swedish public children's channel, Barnkanalen, and was freely available as streaming video through the website www.barnkanalen.se. According to statistics from the Swedish National Broadcast Network (2013), the episodes of Mike the Knight available on the website were watched more than 500,000 times between October 2012 and June 2013. The overall population of children between two and six in Sweden at that time (November 1, 2012) was 569,299 (Statistics Sweden, 2014).

\section{Mike the Knight - Opening sequence of the animated series}

Since our focus in this article is directed towards the representation of gender in transmedial popular culture for children, we will focus particularly on how Mike (as a boy and the central character) and his sister Evie (as the only girl among the main characters) are represented. Important to note, however, is that Evie is a secondary character and not a protagonist in the series. Nevertheless, the fact that she appears in each episode of the series makes her a substantial supporting character. As such, she will have to respond relationally to Mike.

As our first example, we shall look at a sequence from the animated series about Mike the Knight. Since we wanted to look at a part of the series that had been viewed by as many children as possible, we decided to focus on the opening sequence that begins each of the 52 episodes. ${ }^{5}$ Another reason for our interest in the opening sequence is that it can be seen as a form of meta-representation or 'presentation of self' - a signification of the series itself and some key aspects of what it is about. It introduces some of the main themes, characters and settings in an "emblematic" way (Selander, Insulander \& Lindstrand, 2014). The opening sequence also has another function, since it is meant to attract viewers while simultaneously providing a sense of stability and recognisability for those already familiar with the series (cf. Buckingham, 2003, p. 73).

\section{Description of the part of the sequence analysed}

The sequence opens with a shot of Mike in the courtyard, clad in his blue armour. He walks to the centre of the image and says to the camera: "I'm Mike the Knight, and it's time to do it right" (see frames 1 and 2 in fig. 1 above). Trumpets begin to play a fanfare. The camera zooms as Mike draws his sword - producing a 'magical' sound of chimes and a burst of blue glitter (frame 3). The shot dissolves into an image of a castle, set against a blue sky (frames 4 and 5). The theme song begins ("Mike the knight is a brave young hero") 


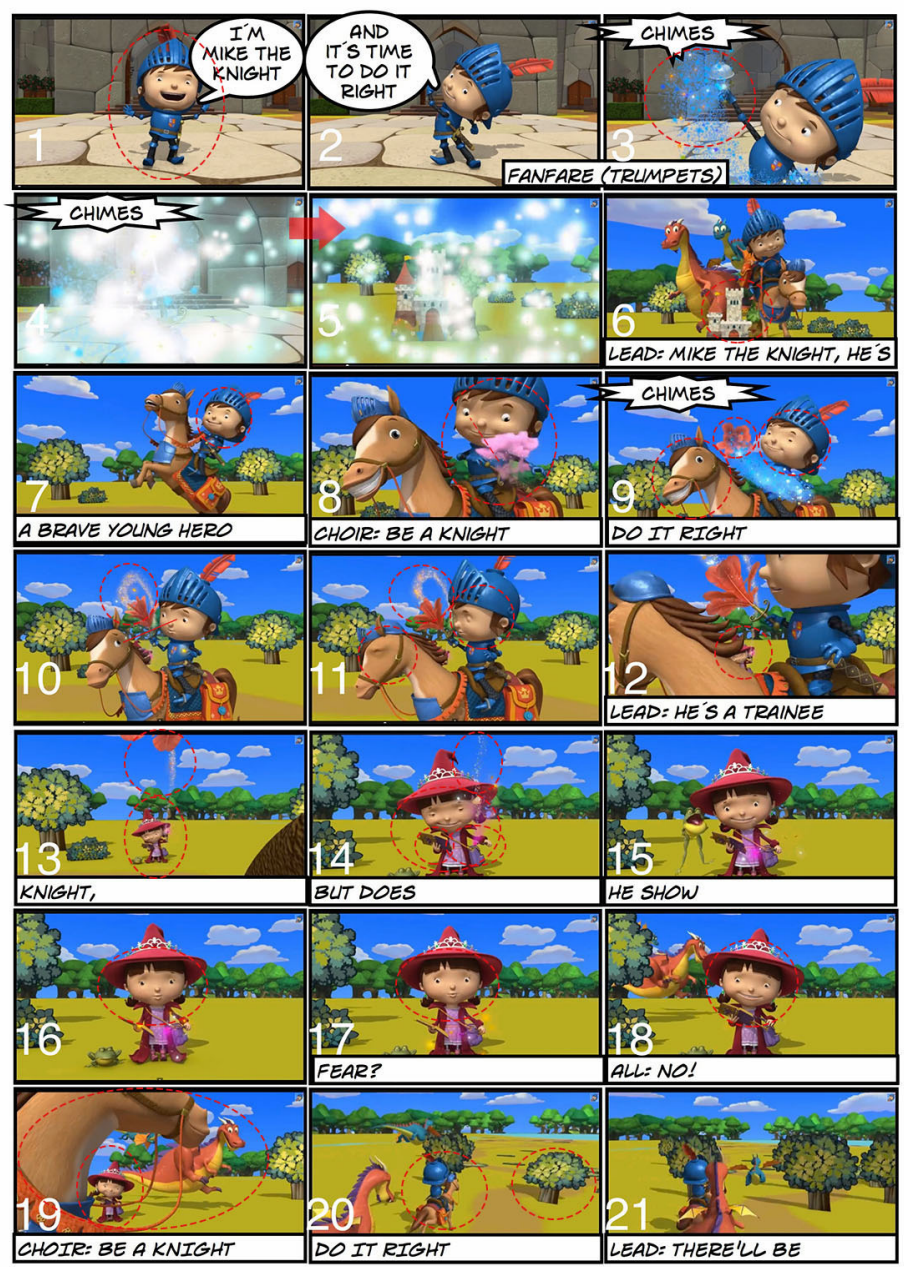

Fig 1. Visual transcript of a selected part of the opening sequence of the television series Mike the Knight (HiT Entertainment, 2013). ${ }^{6}$

as Mike and his horse Galahad appear behind the castle and jump over it - showing that it was only a miniature. His dragon friends, Sparkie and Squirt, run around the castle and join Mike and Galahad (frame 6). At this point, Galahad rears, and both Mike and Galahad smile (frame 7). Then, when Mike proudly draws his sword, something happens. A pink cloud appears around the hilt of the sword (frame 8); and, when he draws it, a 'magical' sound (chimes) and a blue glittering light are produced. The sword is gradually transformed into a red duster (frame 9). A vector (see Kress \& van Leeuwen, 2006) shaped as an arch of 'magical' glitter leads from the sword to a point behind Mike (frame 10). Mike and Galahad look disappointedly at each other (frame 11). They close their eyes and turn to see what the cause of their misfortune is, aided by the vector. This is where Evie first appears, as the vector leads to her magic wand (frames 12-14). She is dressed in red and pink and wears a red crooked hat. There is a green toad (Mr. Cuddles) on the ground by her side. 
At first, Evie looks in her open book of spells and appears to be satisfied (frame 15); but, when she looks up and realizes that her spell has gone wrong, she drops her shoulders and shows a troubled face (frames 16 and 17). However, after a short while, she picks herself up again and smiles (frame 18). At this point, Mr. Cuddles jumps up and croaks. The dragons, Sparkie and Squirt, pass by in the background, and Mike and Galahad continue riding. Evie is obscured by Mike again and literally left behind (frame 19). The camera continues to follow Mike. We pause our analysis at this point and go to the end of the sequence, when Evie is back in picture again.

Evie reappears at the very end of the opening sequence, waiting together with her mother, the Queen, outside the castle of Glendragon when Mike and his friends arrive (figure 2 below, frames 22 and 23).

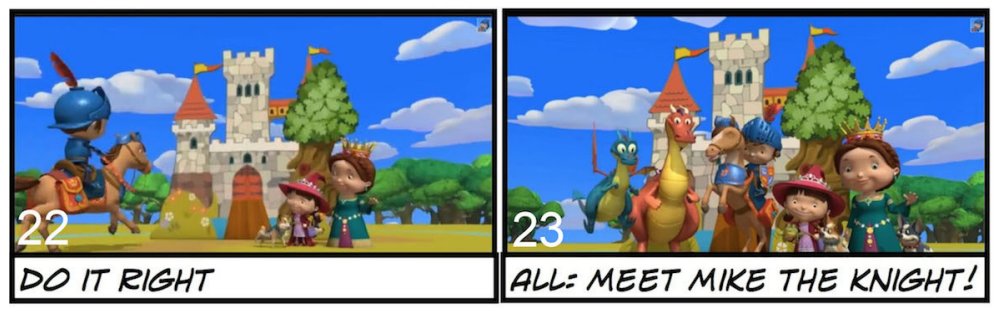

Fig. 2. Visual transcript of a selected part of the opening sequence of the television series Mike the Knight (HiT Entertainment, 2013).

\section{Modes and other resources for meaning-making used in the representation}

The example shows that Evie is represented rather differently than Mike is and that the representations build on a number of modes and other resources for meaning-making.

The series about Mike the Knight obviously bears his name, making him the central character (cf. Soila, 2008, p. 110). In this way, naming contributes to meaning-making in this context (cf. Kress, 2010, pp. 12-14). In contrast to Mike, Evie is not mentioned in the opening sequence.

We also hear Mike talk to us in the beginning of the sequence. He is the only speaking character here, and the mode of speech thereby contributes to the difference in terms of how Mike and Evie are represented.

In a similar way, the lyrics of the opening theme song define Mike as the central character while also building on a certain discourse about boys:

Mike the knight/he's a brave young hero/Be a knight, do it right!/He's a trainee knight/but does he show fear?/No!/Be a knight, do it right!/There'll be trouble/double trouble/But you know it's gonna/be alright./'Cos everyday is an/adventure for Mike the Knight/Be a knight, do it right! (x3)/With Mike the Knight! 
Thus, Mike is presented as brave and adventurous, someone who does not show fear. These characteristics are presented as qualities, signalling a certain view of how boys are or should be. The recurring slogan 'Be a knight, do it right!' similarly articulates certain values regarding what is thought of as 'right' - particularly, that being a knight is something related to boys. If 'knight' is a role or position culturally reserved for boys/males and if to 'do it right' is coupled with this specific position, what values are left for those who do not have access to that role? 'Knight' equals 'right', while 'others' can only aspire for 'good enough' (or worse)?

The mode of colour (Koller, 2008; Kress \& van Leeuwen, 2002; van Leeuwen, 2010) is used to signify 'boyness' (blue) and 'girlness' (red and pink) as an initial demarcation, so to speak. The blue sky in the background makes blue a dominant colour throughout the sequence, linking Mike to the diegetic world visually. Colour is also used to link the duster to Evie.

In a similar way but, perhaps, building on a different discourse, the mode of materiality (cf. Kress \& van Leeuwen, 2001, p. 28) (or, rather, since the sequence is digitally animated, a representation or signification of materials) is used as a resource for inscribing certain gender-related markers in Mike and Evie and, thus, to signify a difference between them.? Mike wears shiny armour, whereas Evie's clothes appear to be made of fabric of some sort more muted colours that (drawing on the old binary way of dividing between 'culture' and 'nature') may signify that she is closer to nature (see van Leeuwen, 2005, pp. 39-40).

Motion is another mode that is used in the animated representation. Mike is constantly moving - either riding or walking. He is at the very centre of the sequence, and his trajectory through the landscape guides the 'camera' action. He is the motor or driving force of the sequence. As a result, there is a steady flow in the progression of events - a constant motion from one point to another. In contrast, Evie does not move her legs at all, and her appearance in the sequence seems to depend on Mike. Instead of moving through the landscape, she 'appears' at different locations. As art historian John Berger (1972, p. 47) concluded, a traditional difference in visual gender representation in Western society is often displayed in the way that "men act, women appear".

There is a noticeable difference in the way Mike and Evie are represented. While Mike is represented as actively moving and taking a leader's role, Evie is represented as a reactor, responding to the actions of Mike (see Kress \& van Leeuwen, 2006, pp. 64-74).

Motion takes place in time and is, thus, related to or dependent on temporality. Pace, tempo and rhythm are different aspects of this relationship, and they are all part of the kit of resources that can be used aesthetically and semiotically within the medium of moving images (see van Leeuwen, 2005). One aspect of this is the fact that the entire opening sequence is designed in a clearly rhythmic fashion, based on the rhythm of the theme song. While Mike's movements and actions serve to drive the sequence forward (narratively and geographically), Evie's appearance slows the overall motion down and momentarily obstructs the flow of the sequence. Her actions thereby constitute a break with the logic of constant motion that has been established as the guiding rule of the mise-en-scène 
(cf. Bazin, 2009; Bordwell \& Thompson, 2012, pp. 112-133) in the sequence. If we look at the opening sequence as a short and dense narrative, her actions can be said to postpone the satisfaction of closure for which the audience is waiting (Bordwell \& Thompson, 2012, pp. 51-57). All of these aspects contribute to the complex representation of Evie in relation to both Mike and the viewer.

The medium of moving images is complex to analyse due to the fact that it operates in both time and space. Composition is related to how space is used as a resource for making-meaning. How (moving) images are designed in terms of spatial relations between elements contributes to how they can be interpreted. In the brief part of the sequence in which Evie is first presented, Mike is in the foreground, and Evie is placed behind him. At first, she is completely obscured by Mike even though she is part of the action. When she is noticed, it is only to show her reaction as she realises that her magic spell has failed. Mike, then, obscures her again as he moves on. At the end of the sequence, Evie and her mother are placed to the right while Mike places himself centrally in front of the castle.

If we look more closely at the visual representations of the opening sequence, we can see that the characters communicate by using certain non-verbal modes such as facial expressions, gestures and postures. In terms of facial expressions, they are used to signal positive and negative feelings in the characters. The dynamics construed through the shift from positive to negative are used as a way to build tension and drama. For example, Evie's magical spell that transforms Mike's sword is given a negative value through the expressions of disappointment on Mike and Galahad. Evie's shift from 'happy' to 'sad' confirms that she has failed. Gestures and postures work in similar ways and can be seen as interrelated with the facial expressions used. By signalling the same thing, they contribute to meaning-making and facilitate viewers' interpretations.

\section{Conclusion of the first analysis}

Our analysis of this brief sequence shows that the representations of Mike and Evie build on a large number of modes and that they are construed very differently. The representation of Mike draws on a discourse about 'boys' as being active, brave, capable and at the centre of attention. The representation of Evie builds on a discourse of 'girls' as either passive or unsuccessful, 'close to nature' and peripheral or in the background. All of the modes that we have found to contribute to the representations of Mike and Evie have pointed in the same directions. In that sense, the film sequence can be said to build on a large degree of modal conformity in that all the modes at play contribute to the general representation of boys and girls. The message concerning what boys and girls are like is, thus, quite clearly communicated. 


\section{Meet Mike - app for tablets and smartphones}

In our second example, we shall look at the 'interactive' digital story Meet Mike, one of three stories available with the app Mike the Knight Storybook Treasury for tablets and smartphones. While this story is free, the other two can be purchased on the app. A click on the icon for Meet Mike leads to a menu where users can choose between three modes of interaction with the story: read aloud narration with manual page turns, read aloud narration with automatic page turns, or no read aloud narration. Words are highlighted as the (male) narrator reads them aloud.

The story can be described as an introduction to the world of Mike the Knight and his family and friends. It is multimodal in the sense that it engages a number of semiotic modes that interplay in the telling of the story: image; written and spoken language with synchronous highlighting of text; sounds; and animations. However, the option to engage with the story without 'read aloud narration' excludes the sound effects that accompany each page.

In total, the story consists of 22 pages (including the menu), but we will focus on one page to exemplify how gender is construed in this digital book.

\section{Female failures}

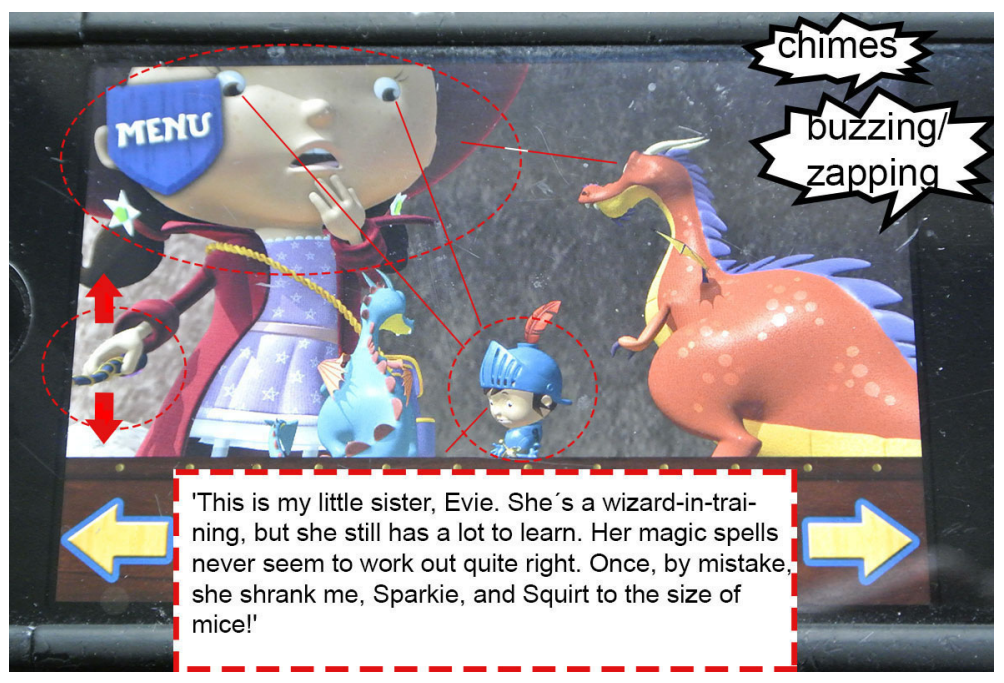

Fig. 3. Visually annotated image of phone screen with page from the app Mike the Knight Storybook Treasury (HiT Entertainment, 2014).

This is where (and how) we first meet with Evie in this story. She is introduced in the ninth 'scene' after the introduction of Mike, Galahad, Mr. Blacksmith, Sparkie and Squirt. Sequence can, thus, be seen as the first mode that adds to the representation of her social significance in relation to Mike. Where she is introduced in the story could be interpreted 
as a way of showing that she is one of the central characters but well below Mike in terms of importance.

Looking at the specific scene, colours are (again) used to signify gender, while dress signifies social roles: Mike as knight and Evie as wizard. Similar to our first example, the represented materiality of their dress also adds to their representation.

Even though this is where Evie is introduced in the story ("This is my little sister, Evie"), the composition of the image construes Mike as the central character by placing him at the centre. Similarly, the verbal introduction, along with the fact that Evie obviously is much bigger than the others, attracts attention, but her gaze forms a vector leading back to Mike. Even when she is in focus, Mike is the central character. This is also implied by the fact that her face is partially obstructed by the menu button.

The visual representation shows that something has happened in this scene, since Mike and the dragons are much smaller than Evie. Mike's and Evie's facial expressions, along with their postures and gaze, also imply that something has gone wrong: Mike looks sad, and Evie looks distressed. This is confirmed by a repeated buzzing/zapping sound that functions as a modality marker (see Kress \& van Leeuwen, 2006, pp. 160-163) and signals that something is out of the ordinary here. The 'magic' sound of chimes suggests that the cause of their misfortune is somehow related to magic (and, thus, paradigmatically related to Evie). Evie's arm and hand (holding a magic wand) are slightly animated, linking the magic mishap to her.

The verbal narrative confirms the story and adds certain values to Evie's actions and abilities. She is presented as an active person, but her actions lead to negative consequences since her magic spells 'never seem to work out quite right'. We are told that Evie has shrunk Mike and his dragon friends 'to the size of mice'.

Apart from contributing to the description of events and consequences, the use of size (shown visually and referred to verbally) also becomes a way of pointing towards groupings and relationships. On the one hand, size (together with the other modes mentioned) indicates who has done what to whom and, at the same time, formally binds Mike and the dragons together as a group while Evie is alone.

The different modes at play cooperate to inform us about who the characters are, the social distance (and/or proximity) between the actors, what has happened and who made it happen. They also tell us how to interpret the events and evaluate them: something has gone very wrong here, and the misfortune of the three friends - Mike and the dragons resulted from Evie's failures.

\section{Same modes, different epistemological commitments: The media context}

So far, we can conclude that numerous modes interact in the representation of Mike and Evie in each of the media texts. A number of them are used in both media contexts, and some of them such as facial expressions, posture, colour, clothing and materiality seem to work in similar ways in both examples. A reason for this may be that they are part of the 
discursive or ideational world of Mike the Knight and, thus, are 'contained' or played out within the story itself.

Other modes such as speech, motion, sequence and composition are more closely connected to the mediation here and are used differently in the two examples. Our intention in this section is to focus briefly on how the use of these latter modes differs between the two media contexts and what social and epistemological implications this has for meaningmaking. We see this as a way to approach some of the affordances of and relationships between different media texts related to the same brand.

\section{Speech}

In the animated opening sequence of the television series, we hear and see Mike talking right to us. In terms of social interaction, he breaks the boundaries between the screen media text and the world of the viewer as he invites the audience to establish a relationship with him directly. What he says ("I'm Mike the Knight, and it's time to do it right") and how he says it (in a medium shot, straight to the camera) also become part of his representation as a determined boy who is ready to take action. Apart from this, speech is not used in the sequence and has no further role in the narration.

In the storybook app, speech has a more central narrative role. It is used as a resource for providing the backbone of the story and, thus, enables the audience to interpret the different interactive elements on the page as part of a multimodal whole. The mode of speech is, therefore, important in an epistemological sense, since it adds information necessary to understand what has happened to the characters on the page/screen. However, instead of promoting a direct relationship between audience and characters, as in the first example, an invisible narrator talks about characters and events. In comparison to the other example, the way speech is used here positions the audience farther away from Mike and his world socially, since they do not have any direct contact with any of the characters.

The differences in how the audience is positioned in these two ways speech is used say something about how we are meant to relate to the text itself. While the animated sequence hints at the interactivity of screen-based media such as digital games and the genre of children's shows on television (and online), the app is designed as a remediation (see Bolter \& Grusin, 2001, pp. 44-50) of books and the social and cultural ritual of 'being read to'. Instead of inviting the audience into the fictitious world itself, it is invited to listen to or read (and look at) stories about this fictitious world. In this sense, the different approaches point to different social practices with different possibilities in terms of the roles offered to audiences. The way the mode of speech is used in the mediation in these two instances signals a difference in terms of the social practices they draw upon: being absorbed into a cinematic and immediate experience, on one hand, and reading a book together with others, on the other. 


\section{Motion}

Motion is another example of a mode that is used in different ways in the two media texts. In the animated opening sequence, motion is at play on (at least) three levels: 1 ) the animation of characters, objects and elements, 2) the motion of Mike and his friends through the landscape and 3) the camera's motion as it follows them in their trajectory. Motion serves to set pace, tempo and rhythm throughout the sequence and defines the space as well. Both of these aspects contribute to the mise-en-scène of the television sequence, which, in turn, puts emphasis on Mike's movements. Evie obstructs the flow, and the resulting change of pace becomes part of the representation of their relationship and of her as a character.

The more static story app also depends on motion but not primarily for the sake of pace. Instead, motion here is a crucial part of the multimodal narration. The few moving (animated) elements serve to guide our understanding of what has happened and who made it happen. Motion is, thus, parallel to speech, central for enabling the audience to (re) construe the story and make sense of what has happened.

Although it is used differently, there is also an important similarity between the two texts in the way motion is employed as a resource for representing Evie. In both texts, motion is used to show/suggest that Evie causes problems that affect Mike negatively.

\section{Temporality}

We mentioned the relationship between motion, on one hand, and pace, rhythm and tempo, on the other. While motion is set in both time and space, pace, rhythm and tempo are organised in time. Temporal aspects are also worth mentioning on their own premises, since they, too, are used differently in the two texts and contribute to the epistemological aspects of the representations in different ways.

Bordwell and Thompson (2013, pp. 79-81) refer to three aspects of time in relation to moving images: story time (the time span of the story), plot time (the time span within the plot) and screen time (the actual time of the screening of a film). Apart from the transition in the very beginning of the opening sequence, there are no cuts in the scene. These three aspects of time, therefore, coincide, adding to the feeling that we get to see all there is to see regarding the events that are represented. The audience 'witnesses' events as they occur on-screen. Even though the sequence is computer-animated and no 'real' camera was used, the traditionally indexical relationship between the camera and the aspects of the world captured on film (cf. Barthes, 1981; Nichols, 2010) is still activated, construing a certain epistemological stance.

In contrast, the story of the app is arranged as a recounting of things that already have happened. Instead of showing events as they occur, we are given clues through different modes that it is up to us - the audience - to make sense of. The multimodal riddle implies another epistemological stance: deductive reasoning and informed interpretation rather than direct witness. 


\section{Composition}

As shown in our first analyses above, the mode of composition also plays an important role in the representations of Mike and Evie in both media texts but in slightly different ways. In the case of the relationship between Mike and Evie in the television sequence, composition primarily deals with how they are placed in relation to each other in space. Mike is placed in front of Evie and obscures her. There is also a difference in terms of where they are placed in relation to the viewer. Evie is placed farther away from the viewer, deeper into the image, than Mike and more in the background in relation to him. Apart from how this affects the representation of Evie in relation to Mike, it also affects our opportunity to interact with her socially, since she is obscured and/or at a greater distance from the viewer.

In the app, composition is more closely connected to the representation of events than characters. Evie's larger size, as opposed to how small Mike and the dragons are, indicates that something has happened. According to Kress and van Leeuwen (2006), the placement of elements within a picture contribute a certain "information value" (pp. 175-214). Elements placed to the left are presented as "given" while elements to the right are "new". The placement of characters in the page of the app suggests that Evie (placed to the left) is her normal self while there is something new about Mike and his friends (to the right). The narrator confirms this interpretation when he tells us that Mike and the dragons have been shrunk.

\section{Concluding discussion}

Our intention in this article has been to show a tendency with regard to the representations of gender in (a specific set of) texts within young children's popular culture today. By looking at two related texts in different media, we have been able to conclude that the representations of boys (Mike) and girls (Evie) are very different in terms of the discourses on which they draw and the subject positions they allow. This is performed by means of a large number of modes, congruently orchestrated either to demarcate the genders or to add more specific aspects to the representations. Mike is consistently represented as being brave, adventurous, active, responsible and central to the different stories. Evie is represented as either inactive or a failure, as a cause of trouble, as comic and as 'close to nature'. In that sense, both of the media texts contributed to the construction of a more general representation of the two characters that appear 'between' the texts or in their intersection. The different modes, afforded by the different media, partake in the complex trans-medial signification of 'Mike' and 'Evie' and, thereby, contribute to making 'Mike-andEvie-as-signs' more detailed, varied and 'modally rich' even though they did not contribute to making the specific characters more complex.

Another less usual aspect of trans-mediality (e.g., Jenkins, 2006) can be noticed in the examples presented here. Whereas the notion usually refers to the expansion of narratives, characters and concepts between/beyond media texts, the expansion here has more to do 
with multimodality as different texts contribute different modes in the representations of the fictitious world. This could, perhaps, be seen as another dimension of trans-mediality that may have epistemological consequences for the meaning-making audience. Assuming that gender roles and worldviews are learned early on in life, the texts we have looked at here can be regarded as resources for learning. As such, they can be said to work quite well (bearing in mind that learning is a process and that it does not necessarily have to be related to 'truth'). Many various modes are engaged in the different representations, constructing a very rich image (in terms of detail and modal variation) of how boys and girls 'are' (according to these particular texts!). The representations are also triggered by narratives designed to correspond to a presumed idea about interests, experiences and cognitive skills of the audience.

We have pointed towards the importance of critical reflection regarding what may appear to be 'natural' ways of representing gender and other social dimensions and categories in different kinds of texts. After all, the television series was aired by Swedish national television after thorough consideration.

However, it is also important to remember that social construction does not necessarily follow causal structures. The fact that aspects of the world are represented in certain ways does not necessarily mean that young audiences have to play along. As Gunther Kress and Theo van Leeuwen (2001, p. 8) argue, communication has not occurred until someone has made an interpretation of some kind. It is, therefore, important to look beyond the texts to see how an audience of young and competent meaning-makers deal with them.

While young Alice's descriptions in the opening section of this article indicate that she has acknowledged some central aspects of the problematic representations of gender in popular culture, she actively circumvents them and the expectations that follow by choosing less problematic characters in her play. But it is still a fact that she needs to be creative in order to find a role that suits her interests. The essentialist discourses about boys and girls on which many representations in popular culture draw make this a challenge for many children today.

\section{Notes}

1 The research project REMAKE. Representations, resources and meaning-making. The Middle Ages as a knowledge domain in different learning contexts is financed by the Swedish research council (Vetenskapsrådet) 2012-2015.

2 For a more in-depth analysis and reflection on children's strategies in relation to gender issues, see Bronwyn Davies (2003).

3 The results presented in the report are based on 'content analyses of gender roles in popular films across the 10 most profitable territories internationally (Australia, Brazil, China, France, Germany, India, Japan, Russia, South Korea, and the United Kingdom) as reported by the Motion Picture Association of America (MPAA) in 2012' (Smith et al., 2013). 
4 We build our understanding of discourse on Foucault's (1969/1972) definition, as 'practices which form the objects of which they speak' (p. 49).

5 The sequence we have analysed can be viewed on Mike the Knight's YouTube channel: https://www. youtube.com/watch?v=jPIwUyXhug4.

6 The images included in this section of the article are screenshots from part of the opening sequence. We have pasted them into a cartoon-like format and added notes regarding speech, theme song lyrics and salient sounds. The black frames around the images are part of the cartoon-like format and were not included in the video material.

7 For a discussion about the role of materiality in semiosis, see Björkvall \& Karlsson, 2011.

\section{References}

Aarseth, E. (2006). The culture and business of cross-media productions. Popular Culture: The International Journal of Media and Culture, 4(3), 203-211.

Baldry, A. \& Thibault, P.J. (2006). Multimodal Transcription and Text Analysis: A Multimedia Toolkit and Course Book. London: Equinox.

Bar, A. (2013). Meet Mike the knight! Opening sequence of television series. Retrieved April 14, 2015, from https://www.youtube.com/watch?v=jPIwUyXhug4. London, New York \& Ontario: HiT Entertainment \& Nelvana.

Barnkanalen [Swedish children's channel] (2015). Website. Retrieved April 14, 2015, from http://www.svt.se/ barnkanalen.

Barthes, R. (1981). Camera Lucida: Reflections on Photography. New York: Hill and Wang.

Bazin, A. (2009). What Is Cinema? Montreal: Caboose.

Berger, J. (1972). Ways of Seeing. London: Penguin Books.

Björkvall, A. \& Karlsson, A.-M. (2011). The materiality of discourses and the semiotics of materials: A social perspective on the meaning potentials of written texts and furniture. Semiotica, 187(1/4), 141-165.

Bolter, J.D. \& Grusin, R. (2000). Remediation: Understanding New Media. Cambridge, MA: The MIT Press.

Bordwell, D. \& Thompson, L. (2012). Film Art: An Introduction. Tenth edition. New York: McGraw-Hill.

Buckingham, D. (2003). Media Education: Literacy, Learning and Contemporary Culture. London: Cambridge: Polity Press.

Buckingham, D. (2007). Beyond Technology: Children's Learning in the Age of Digital Culture. Cambridge: Polity Press.

Buckingham, D. \& Willett, R. (Eds.) (2013). Digital Generations: Children, Young People, and New Media. New York: Routledge.

Butler, J. (1988). Performative acts and gender constitution: An essay in phenomenology and feminist theory. Theatre Journal, 40(4), 519-531.

Butler, J. (1990). Gender Trouble: Feminism and the Subversion of Identity. London and New York: Routledge.

Collins, P.H. (2000). Black Feminist Thought: Knowledge, Consciousness and the Politics of Empowerment. New York: Routledge.

Davies, B. (2003). Frogs, Snails and Feminist Tales: Preschool Children and Gender. Second edition. New York: Hampton Press.

De Lauretis, T. (1987). Technologies of Gender: Essays on Theory, Film and Fiction. Bloomington and Indianapolis: Indiana University Press.

Diekman, A.B. \& Murnen, S.K. (2004). Learning to be little women and little men: The inequitable gender equality of non-sexist children's literature. Sex Roles, 50(5-6), 373-385.

DuCille, A. (1996). Skin Trade. Cambridge, MA: Harvard University Press. 
Du Gay, P. (Ed.) (1997). Production of Culture/Cultures of Production. London: SAGE/The Open University.

Dyer, R. (2000). The Matter of Images: Essays on Representation. London: Routledge.

Foucault, M. (1969/1972). The Archaeology of Knowledge. London: Routledge.

Gee, J.P. \& Hayes, E.R. (2011). Language and Learning in the Digital Age. New York: Routledge.

Global License (2014). Retrieved February 27, 2015, from http://www.licensemag.com/license-global/search? keys=Mike\%20the\%20knight.

Grauerholz, L. \& Pescosolido, B.A. (1989). Gender representation in children's literature: 1900-1984. Gender and Society, 3(1), 113-125.

Götz, M., Hofmann, O., Brosius, B. et al. (2008). Gender in children's television worldwide. Results from a media analysis in 24 countries. Televizion 21/2008/E, 4-9.

Hall, S. (Ed.) (1997). Representation: Cultural Representations and Signifying Practices. London: SAGE/The Open University.

Hamilton, M.C., Anderson, D., Broaddus, M. et al. (2006). Gender stereotyping and under-representation of female characters in 200 popular children's picture books: A twenty-first century update. Sex Roles, 55(11-12), 757-765.

Hodge, R. \& Kress, G. (1988). Social Semiotics. Ithaca, New York: Cornell University Press.

Jenkins, H. (2006). Convergence Culture: Where Old and New Media Collide. New York: NYU Press.

Jewitt, C. (ed.) (2011). The Routledge Handbook of Multimodal Analysis. London: Routledge.

Jones, A. (1992). Feminism, incorporated: Reading 'postfeminism' in an anti-feminist age. Afterimage, 20(5), 10-15.

Jones, A. (Ed.) (2006). The Feminist and Visual Culture Reader. New York: Routledge.

Koller, V. (2008). 'Not just a colour': Pink as a gender and sexuality marker in visual communication. Visual Communication, 7(4), 395-423.

Kress, G. (1993). Against arbitrariness: The social production of the sign as a foundational issue in critical discourse analysis. Discourse \& Society, 4(2), 169-191.

Kress, G. (1997). Before Writing: Rethinking the Paths to Literacy. London: Routledge.

Kress, G. (2003). Literacy in the New Media Age. London: Routledge.

Kress, G. (2010). Multimodality: A Social Semiotic Approach to Contemporary Communication. London: Routledge.

Kress, G. \& van Leeuwen, T. (2001). Multimodal Discourse. The Modes and Media of Contemporary Communication. London: Arnold.

Kress, G. \& van Leeuwen, T. (2002). Colour as a semiotic mode: Notes for a grammar of colour. Visual Communication, 1(3), 343-368.

Kress, G. \& van Leeuwen, T. (2006). Reading Images: The Grammar of Visual Design. Second edition. London \& New York: Routledge.

Lemke, J. (2004). Critical analysis across media: Games, franchises and the new cultural order. Paper presented at the First International Conference on CDA, Valencia, Spain. Retrieved March 14, 2014, from http://www.jaylemke.com/all-publications.

Lemke, J. (2009). Multimodal genres and transmedia traversals: Social semiotics and the political economy of the sign. Semiotica, 173(1/4), 283-297.

Marsh, J., Brooks, G., Hughes, J. et al. (2005). Digital beginnings: Young children's use of popular culture, media and new technology. Report of the 'Young children's use of popular culture, media and new Technology' project. Literacy Research Centre, University of Sheffield.

Mike the Knight. Official website. Retrieved March 1, 2015, from http://www.miketheknight.com.

Mike the Knight Storybook Treasury (2014). Digital app for iPhone and iPad. London \& New York: HiT Entertainment. 
Nichols, B. (2010). Introduction to Documentary. Second edition. Bloomington and Indianapolis: Indiana University Press.

Rogoff, I. (2002). Studying visual culture. In N. Mirzoeff (Ed.). The Visual Culture Reader(pp. 24-36). Second edition. London and New York: Routledge.

Selander, S., Insulander, E. \& Lindstrand, F. (2014). Thematic and emblematic features of the Middle Ages: Theoretical tools for analysing multimodal texts. Paper presented at the 7th International Conference on Multimodality, 7ICOM, Hong Kong, June 11-13, 2014.

Selander, S. (2008). Designs for learning - A theoretical perspective. Designs for Learning, 1 (1), 10-22.

Selander, S. (2015). Conceptualization of multimodal and distributed designs for learning. In Gros, B., Kinshuk. \& Maina, M. (Eds.) The Futures of Ubiquitous Learning: Learning Designs for Emerging Pedagogies, Heidelberg, New York, Dordrecht \& London: Springer, 97-113.

Smith, S.L., Choueiti, M., Prescott, A. et al. (2013). Gender roles and occupations - A look at character attributes and job-related aspirations in film and television. Geena Davis Institute on Gender and Media. Retrieved December 20, 2014, from http://www.seejane.org.

Soila, T. (2008). Berättelse [Narrative]. In A. Koivunen (Ed.). Film och andra rörliga bilder - en introduktion [Film and Other Moving Images - An Introduction]. Stockholm: Raster Förlag, 105-126.

Statistics Sweden (2014). Online resource, retrieved April 1, 2014, from http://www.statistikdatabasen. scb.se/pxweb/sv/ssd/START__BE__BE0101__BE0101A/FolkmangdNov/table/tableViewLayout1/ ?rxid=40cff99d-178f-4a1c-907e-590f27b1d4a7.

Sturken, M. \& Cartwright, L. (2009). Practices of Looking: An Introduction to Visual Culture. Oxford: Oxford University Press.

Tepper, C.W. \& Cassidy, K.W. (1999). Gender differences in emotional expression in children's literature. Sex Roles, 40(3-4), 265-280.

van Leeuwen, T. (2010). The Language of Colour. An Introduction. London: Routledge.

van Leeuwen, T. (2005). Introducing Social Semiotics. London: SAGE.

Fredrik Lindstrand

Senior lecturer

Konstfack University College of Arts, Crafts and Design, Sweden

fredrik.lindstrand@konstfack.se

Eva Insulander

Senior lecturer

Department of Education

Stockholm University, Sweden

eva.insulander@edu.su.se

Staffan Selander

Professor

Department of Computer- and Systems Sciences (DSV)

Stockholm University, Sweden

staffan.selander@dsv.su.se 